\title{
Return to play after hamstring injuries in football (soccer): a worldwide Delphi procedure regarding definition, medical criteria and decision-making
}

\author{
Nick van der Horst, ${ }^{1}$ FJG Backx, ${ }^{1}$ Edwin A Goedhart, ${ }^{2}$ Bionka MA Huisstede, ${ }^{1}$ on behalf \\ of HIPS-Delphi Group
}

'Department of Rehabilitation, Nursing Science \& Sports, Rudolf Magnus Institute of Neurosciences, University Medical Center Utrecht, Utrecht, The Netherlands ${ }^{2}$ FIFA Medical Center Royal Netherlands Football Association, Zeist, The Netherlands

\section{Correspondence to} Dr Nick van der Horst, Department of Rehabilitation, Nursing Science \& Sports, University Medical Center Utrecht, Rudolf Magnus Institute of Neurosciences, P.O Box 85500, Utrecht 3508 GA, The Netherlands: n.vanderhorst-3@umcutrecht.nl

Accepted 10 March 2017 Published Online First 30 March 2017

\section{CrossMark}

To cite: van der Horst $N$, Backx FJG, Goedhart EA et al. Br J Sports Med 2017:51:1583-1591.

\section{ABSTRACT}

There are three major questions about return to play (RTP) after hamstring injuries: How should RTP be defined? Which medical criteria should support the RTP decision? And who should make the RTP decision? The study aimed to provide a clear RTP definition and medical criteria for RTP and to clarify RTP consultation and responsibilities after hamstring injury. The study used the Delphi procedure. The results of a systematic review were used as a starting point for the Delphi procedure. Fifty-eight experts in the field of hamstring injury management selected by 28 FIFA Medical Centres of Excellence worldwide participated. Each Delphi round consisted of a questionnaire, an analysis and an anonymised feedback report. After four Delphi rounds, with more than $83 \%$ response for each round, consensus was achieved that RTP should be defined as 'the moment a player has received criteria-based medical clearance and is mentally ready for full availability for match selection and/or full training'. The experts reached consensus on the following criteria to support the RTP decision: medical staff clearance, absence of pain on palpation, absence of pain during strength and flexibility testing, absence of pain during/after functional testing, similar hamstring flexibility, performance on field testing, and psychological readiness. It was also agreed that RTP decisions should be based on shared decision-making, primarily via consultation with the athlete, sports physician, physiotherapist, fitness trainer and team coach. The consensus regarding aspects of RTP should provide clarity and facilitate the assessment of when RTP is appropriate after hamstring injury, so as to avoid or reduce the risk of injury recurrence because of a premature RTP.

\section{INTRODUCTION}

Hamstring injuries are the most prevalent muscle injury in football, and 12\%-33\% of athletes with a hamstring injury experience a recurrence within a year after the initial injury. ${ }^{1-5}$ The burden of hamstring injury is high: for the professional player an average of 18 days and 3 matches missed per season, ${ }^{5}$ and for the professional football club an average of 15 matches and 90 days missed per season. ${ }^{5}$ The inability to play because of injury, but also because of unnecessary prolonged absence from play during rehabilitation, affects the individual player and team performance. Lower injury burden and higher match availability are significantly associated with a higher final league ranking, points per league match and success in the Union of
European Football Association Champions league or Europa League. ${ }^{6}$

Reducing the risk of injury recurrence is a key priority after the initial hamstring injury. Recurrent injuries require more extensive rehabilitation than the primary injury, and previous injury is an undisputed risk factor for future injury. ${ }^{3-10}$ Particularly alarming is the observation that recurrence rates have not improved over the last 30 years. ${ }^{11-13}$ High recurrence rates might be due to inadequate rehabilitation and/or premature return to play (RTP). ${ }^{14} 15$ Of all recurrences, more than half occur within the first month after RTP. ${ }^{10} 16$ This has prompted interest in RTP after hamstring injury. ${ }^{17-21}$

Unfortunately, different concepts of RTP make it difficult to analyse and compare various studies of RTP after hamstring injury. ${ }^{22} 23$ It is recognised that diversity in definitions and methodologies contributes to significant differences in the results and conclusions obtained from sports injury research. ${ }^{24-27}$ Furthermore, in accordance with the Strategic Assessment of Risk and Risk Tolerance framework (figure 1), it is commonly agreed that any RTP decision should be based on an assessment of the risk and the acceptable risk tolerance threshold. $^{28} 29$ So far, no studies have specified how risk should be assessed when clinicians are faced with the RTP decision after hamstring injury, although this moment is vital if injury recurrence is to be prevented. A recent systematic review of the literature showed that there is great diversity in how RTP after hamstring injury is defined and which criteria are used to assess RTP readiness. ${ }^{22}$ Also, because multiple stakeholders have their own reasons why RTP should be accelerated or delayed, it is imperative to provide clarity on who is to be consulted and who is responsible for the RTP decision.

The aim of this Delphi procedure was to determine, based on expert consensus, a clear definition of and medical criteria for RTP and to clarify responsibilities for RTP after hamstring injury.

\section{MATERIALS AND METHODS}

\section{Study design and setting}

This Delphi study was part of the Hamstring Injury Prevention Strategies project, which includes several studies focusing on the prevention of hamstring (re-)injuries. The present Delphi procedure is one of these studies and aimed to achieve consensus on the terminology, definition and medical criteria for RTP, and who should be involved and responsible for the 

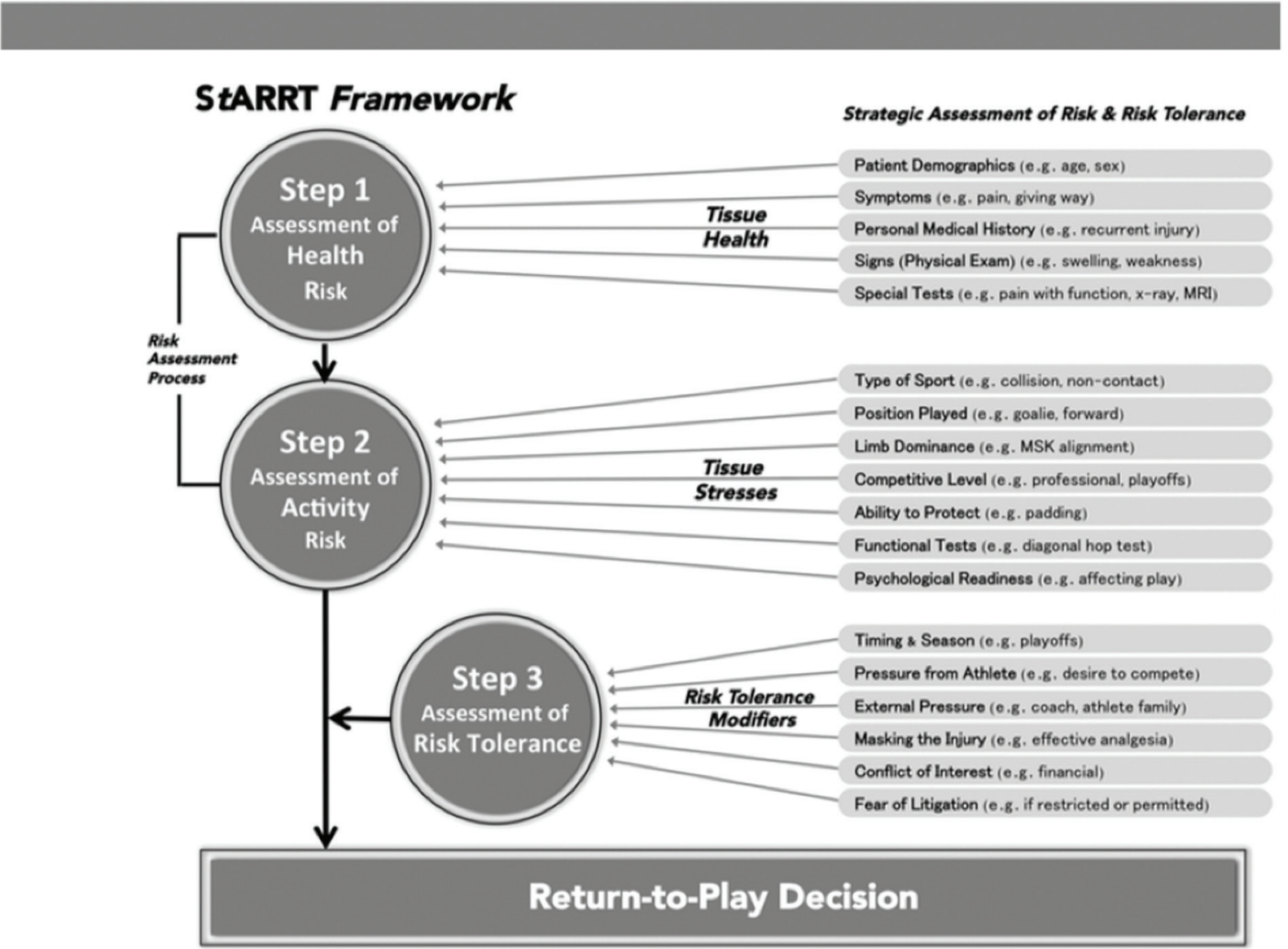

Figure 1 The Strategic Assessment of Risk and Risk Tolerance (StARRT) framework for RTP decisions. ${ }^{28}$ RTP, return to play.

RTP decision after hamstring injury. The study was carried out by the Department of Rehabilitation, Physical Therapy Science, and Sport at the University Medical Centre of Utrecht, the Netherlands. Before the start of this project, a systematic review of the definition of, and criteria for, RTP after hamstring injury was performed. ${ }^{22}$ The results of the systematic review were used as a starting point for the Delphi procedure.

\section{Delphi procedure}

We used a series of sequential questionnaires or 'rounds', interspersed by feedback, to achieve consensus of opinion among a panel of experts. ${ }^{30} 31$ This scientific method was originally developed in the 1950s and has been effectively used in sports medicine research. ${ }^{32-35}$ Each Delphi round comprised a questionnaire, an analysis and a feedback report.

\section{Steering committee}

The steering committee that facilitated and guided this Delphi study consisted of a full professor in sports medicine, a senior researcher with experience in Delphi procedures, a team doctor of a national football team and a PhD student. All members have a clinical (sports medicine, (sports) physical therapy) and scientific background. The steering committee was responsible for preparing and analysing the questionnaires and for reporting the results in anonymised feedback reports.

\section{Expert panel}

The FIFA Medical Centres of Excellence (FMCoEs) have a demonstrable record of leadership in football medicine and have been accredited through a strict selection process by FIFA. These centres provide a network of knowledge and experience in research and clinical management of hamstring injuries. All FMCoEs $(n=40)$ were invited to select up to three experts in hamstring injury management to participate in our Delphi study, adhering to the inclusion criteria as listed in Box 1. These criteria are commonly used when selecting experts who participate in a Delphi study. ${ }^{33}$ 36-38 After selection, the steering committee contacted all experts via email to provide information about the aim, methods and privacy statements for the Delphi study.

\section{Procedure}

Online surveys were used and adhered to principles of respondent anonymity and feedback between rounds. ${ }^{30}$ For all Delphi

Box 1 Experts' inclusion criteria for participation to the Delphi study

The selected FIFA Medical Centre of Excellence considers this expert to be a key person in the field of hamstring injury management

- The expert is a researcher OR medical / health professional with experience in hamstring injury rehabilitation in a sport setting

- The expert has sufficient knowledge of English language

- The expert has an evidence-based attitude 
Box 2 Items* included to start discussion on definition and criteria for RTP after hamstring 182 injury

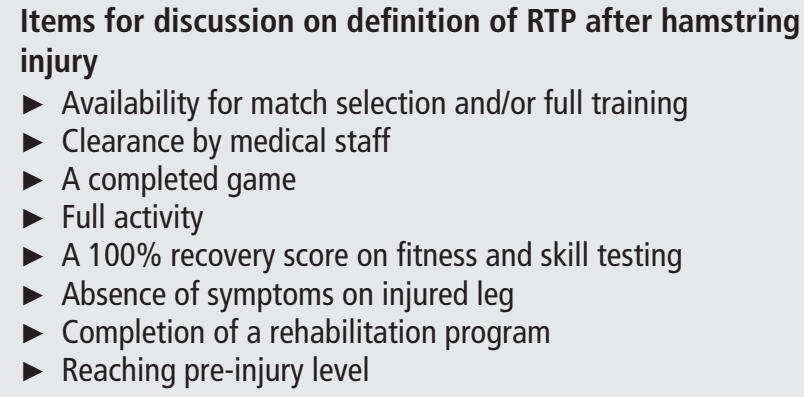

Items for discussion on criteria for RTP after hamstring injury

- Medical staff clearance

- Absence of pain

- Similar hamstring strength

- Similar hamstring flexibility

- Functional performance

${ }^{\star}$ All items were derived from a systematic review.on definition and criteria for RTP after hamstring injury. ${ }^{22}$

rounds, experts received an invitation via email with a link to an online questionnaire. Experts were given 6 weeks to complete the questionnaire, with reminders emailed at 3 and 5 weeks. A structured web-based questionnaire was developed consisting of three parts: part I for general questions about RTP consultation and responsibilities, part II for the definition of RTP and part III for criteria to support the RTP decision after hamstring injury. During the whole procedure, we used structured questions, such as 'Do you feel this item should be a part of the RTP definition?' or 'Do you feel this item should be a criterion to support the RTP decision after hamstring injury?' Answer options were 'yes', 'no' or 'no opinion'. Experts were encouraged to provide justification for their answers. Topics that did not reach consensus were included in the next Delphi round. For some questions, the steering committee added a 'note from the steering committee', based on expert opinion or the literature.

\section{Cut-off point for consensus}

A cut-off score of $\geq 70 \%$ agreement was proposed for consensus because this cut-off is often used in Delphi procedures. ${ }^{36} 3739$

\section{RTP terminology}

The expert panel was asked to reach consensus regarding which term for RTP in sports should be adopted (eg, return to sport, RTP, return to competition, etc).

\section{Definition of RTP after a hamstring injury}

Results from the systematic review ${ }^{22}$ that we conducted to inform the Delphi process (Box 2) were used as the starting point for the Delphi process for the definition of RTP. Experts were asked which terms should or should not be included in the RTP definition. Experts were also invited to open-ended question regarding the definition of RTP after hamstring injury.
Medical criteria to support the RTP decision after a hamstring injury

Similar to the definition of RTP, a systematic review of the medical criteria used to support the RTP decision after hamstring injury was used as a starting point for this part of the Delphi process. ${ }^{22}$ Experts were asked which criteria should or should not be used to support the final RTP decision and to provide any additional criteria they thought relevant.

\section{RTP responsibilities}

The relevant stakeholders in RTP decision-making were initially identified from the published literature. ${ }^{40}{ }^{41}$ Experts were additionally asked to name other stakeholders involved in RTP consultation and decision-making.

\section{Data analysis}

Data from all Delphi rounds were extracted from the online survey database to SPSS V.22.0, and anonymously reported in feedback reports. For questions with a 'yes/no/no opinion' answer format, the percentage of answers in each category was calculated. Qualitative data (ie, expert answers and justifications) were analysed by content analysis and discussed by the steering committee. This information and the main arguments of the experts were summarised and included in a 'note from the steering committee' and added to each question. If consensus was not reached on a topic, these notes were included in a follow-up question on a related subject, used to rephrase the original question or to compose new questions on this topic.

\section{RESULTS}

After four consecutive Delphi rounds, performed between July 2015 and July 2016, full consensus was achieved on three main content areas. The final consensus is presented in the RTP model for hamstring injuries in football (figure 2).

\section{Expert panel}

Fifty-eight experts were recruited from 28 FMCoEs worldwide (participating experts are included in the acknowledgements section). Eleven FMCoEs did not respond to the invitation and one FMCoE could not participate due to migration. The participating experts had a range of experiences in clinical practice and research, including full professor, medical director, lecturer, sports physician, orthopaedic surgeon, physical therapist, performance coach, athletic trainer and/or clinical researcher. Most members had written multiple high-quality international publications, and had an average of 15.8 ( $\mathrm{SD} \pm 8.2$; range: $3-35$ ) years of practical experience in the field of hamstring injury management in football. The response rates in this Delphi procedure were 93\% (round 1), 90\% (rounds 2 and 3) and 84\% (round 4).

\section{Cut-off point for consensus}

In Delphi round 1, the expert panel agreed that a cut-off score of $\geq 70 \%$ would be used to define consensus.

\section{RTP terminology}

In Delphi round 1, most experts chose either 'return to play' or 'return to competition' as the term to define RTP. In Delphi round 2, consensus was reached to adopt return to playincluding its acronym RTP — as the term for return to play in sports, with the justification being that it is simple, well-known and adopted worldwide at many levels, including conferences and publications. It was agreed that 'return to competition' 


\section{RTP MODEL FOR HAMSTRING INJURIES IN FOOTBALL}

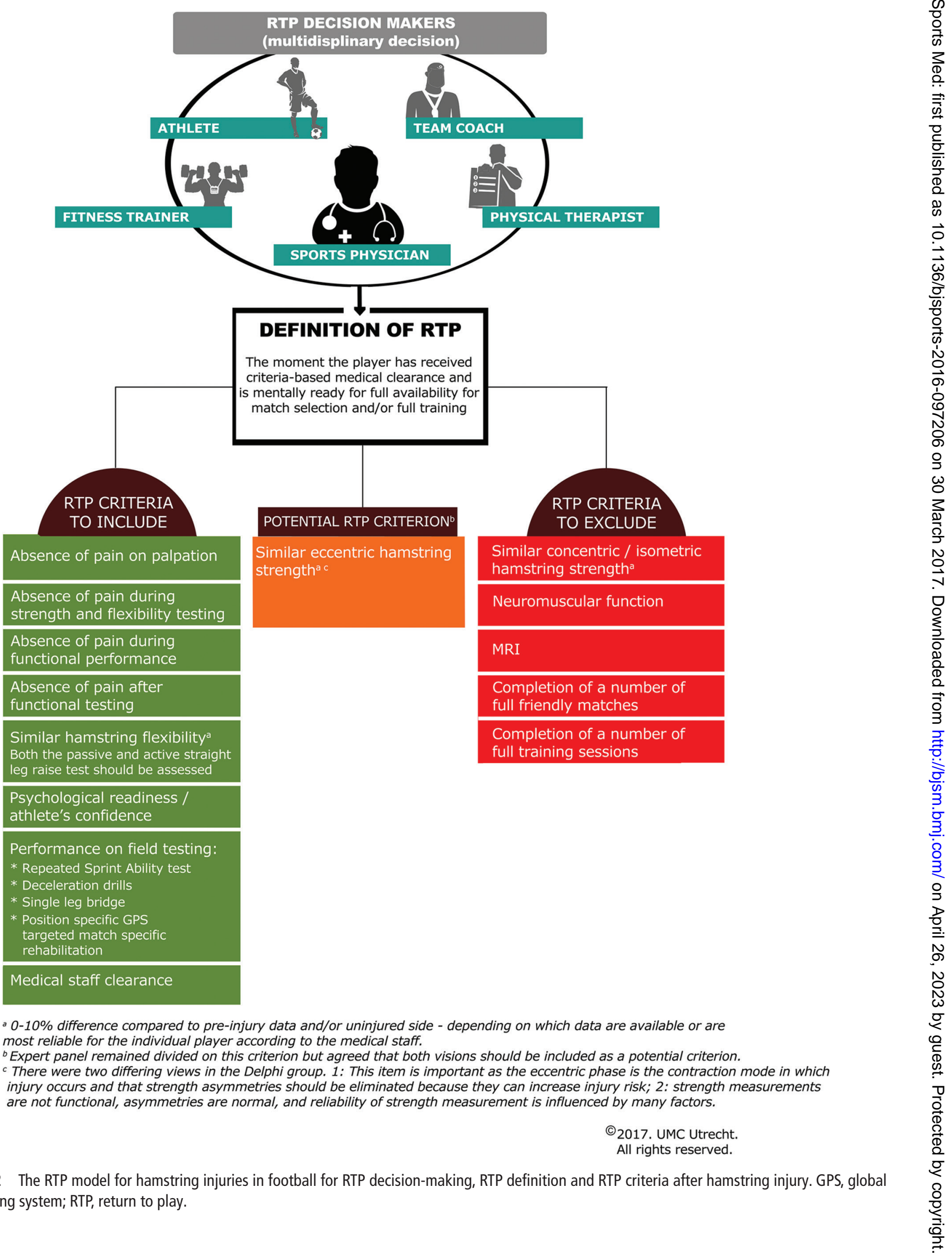

Figure 2 The RTP model for hamstring injuries in football for RTP decision-making, RTP definition and RTP criteria after hamstring injury. GPS, global positioning system; RTP, return to play. 
should be included in the definition of the generic term 'return to play'.

\section{Definition of RTP after a hamstring injury}

In the first Delphi round, consensus was reached to include 'availability for match selection and/or full training' and 'clearance by medical staff' as part of the RTP definition after a hamstring injury. There was also consensus that 'a completed game' should not be included in the RTP definition because RTP clearance should be given before a player resumes play and availability to play a match might be based on non-medical (eg, tactical, teambased) factors or decisions. The expert panel suggested considering inclusion of 'a player's positive mental attitude (athlete's readiness)' in the definition of RTP after hamstring injury.

In Delphi rounds 2 and 3, there was consensus that 'full activity', 'a $100 \%$ recovery score on fitness and skill testing', 'absence of symptoms on injured leg', 'completion of a rehabilitation programme' and 'reaching preinjury level' should not be included in the definition of RTP after hamstring injury. The rationale was that these items are not specific enough and/or should be considered as criteria for RTP, but not for RTP definition. In Delphi round 3, consensus was achieved on including 'a player's positive mental attitude (athlete readiness)' in the definition of RTP, because mental readiness was considered important to eliminate anxiety and because a positive mental attitude is perceived to diminish the risk of reinjury and to improve performance.

The expert panel reached consensus that RTP should be defined as 'the moment a player has received criteria-based medical clearance and is mentally ready for full availability for match selection and/or full training'.

\section{Medical criteria to support the RTP decision after a hamstring injury}

After discussion and specification of criteria through all rounds of this Delphi consensus procedure, the following criteria were included: medical staff clearance, similar hamstring flexibility (compared with preinjury data and/or uninjured side, depending on which data are available or are most reliable for the individual player according to the medical staff), performance on field testing, psychological readiness, and absence of pain on palpation, strength testing, flexibility testing and/or functional testing. Additionally, the expert panel stated that specification of criteria was required. The experts agreed that 'similar hamstring flexibility' could involve a $0 \%-10 \%$ difference between injured and uninjured leg or compared with preinjury data. The expert panel reached consensus that hamstring flexibility should be assessed by means of both the active and the passive straight leg raise test. The rationale was that the passive straight leg raise test is considered as the gold standard for hamstring flexibility measurements in daily practice, and it is important to measure both the active and passive components. ${ }^{42}$

With regard to 'performance on field testing', the expert panel mentioned a number of field tests used in clinical practice to support the RTP decision after hamstring injury (see table 1). In Delphi round 3, the experts were asked whether they had practical experience with other field tests of functional performance and whether they would recommend using these tests to support the RTP decision after hamstring injury (see table 1). Consensus was reached that the repeated sprint ability test ${ }^{43}$ deceleration drills, single leg bridge and position-specific global positioning system (GPS)-targeted match-specific rehabilitation were relevant functional performance tests to support the RTP decision
Table 1 Expert advice on performance on field testing to assess eligibility for RTP after hamstring injury

\begin{tabular}{llcl}
\hline Clinical test & $\%^{*}$ & Clinical test & $\%^{*}$ \\
\hline $\begin{array}{l}\text { Position-specific GPS-targeted } \\
\text { match-specific rehabilitation }\end{array}$ & 82 & 20 m sprint & 57 \\
\hline $\begin{array}{l}\text { Repeated sprint ability test } \\
\text { Single leg bridge }\end{array}$ & 76 & Nordic hamstring exercise & 55 \\
Deceleration drills & 71 & Triple hop test & 53 \\
Acceleration drills & 71 & Muscular endurance & 45 \\
T-test & 68 & YoYo/shuttle run test & 43 \\
40 m sprint & 63 & Speed testing & 39 \\
H-test & 61 & Functional movement screen & 35 \\
\hline
\end{tabular}

* Percentage of experts stating this test could be suggested for functional performance assessment. Consensus (eg, $\geq 70 \%$ ) was only achieved for the tests presented in bold letters.

GPS, global positioning system; RTP, return to play.

after hamstring injury. In addition to the consensus achieved on the inclusion of these tests, the experts frequently commented that performance on field-testing should involve explosive movements to mimic football performance.

No consensus was reached for the inclusion or exclusion of 'similar eccentric hamstring strength' as a criterion to support the RTP decision after hamstring injury. The expert panel remained divided, with two irreconcilable opinions: one group of experts stated that similar eccentric strength assessment is important as a criterion for RTP as the eccentric phase is also the contraction mode in which injury occurs, and strength asymmetries should be eliminated because they can increase the risk of injury. The other group of experts stated that strength measurements are not functional, asymmetries are normal, and that too many factors influence the measurement of strength, so that reliable measurements are not possible. In Delphi round 4 , consensus was reached to add 'similar eccentric hamstring strength' (compared with preinjury data and/or uninjured side, depending on which data are available or are most reliable for the individual player according to the medical staff) as a potential criterion to support the RTP decision provided that both sides of the argument would be described in the consensus.

The experts agreed that 'neuromuscular function' should not be included as a criterion for RTP after hamstring injury. Although the experts stated that neuromuscular function is always important, specifying the concept and assessment of neuromuscular function would go beyond the scope of this Delphi procedure and was therefore not indicated as a criterion. The exclusion of MRI assessment as a potential criterion for RTP decision-making after hamstring injury was supported by recent studies. ${ }^{2044}$ Baseline MRI parameters are not predictive of hamstring reinjury, and MRI is not of additional predictive value compared with baseline patient history and clinical examination alone. ${ }^{2045}$ Completion of a number of full training sessions was also excluded as a criterion as 'availability for full training and match selection' was already included in the definition of RTP after hamstring injury.

\section{RTP responsibilities}

In Delphi round 2, consensus was reached that the sports physician, physiotherapist, fitness trainer and athlete are the primary stakeholders to be involved in RTP decision-making. There was discussion about the role of the team coach, who not being medically qualified might allow an early RTP to improve team performance, despite potential medical risks. However, in Delphi 
round 3, the expert panel reached consensus on the inclusion of the team coach for RTP consultation because of his/her ability to assess the sport-specific performance level, his/her role in team selection and his/her function in the multidisciplinary team staff. The sports physician (who often acts as the head of the medical staff) was chosen to be ultimately responsible for the RTP decision, based on the input provided by the multidisciplinary team and the athlete.

\section{DISCUSSION}

This Delphi study involving 58 experts from 28 FIFA Medical Centres of Excellence worldwide reached consensus on a clear definition and medical criteria for RTP after hamstring injury and who should be consulted about RTP and take ultimate responsibility for the RTP decision (see figure 2).

\section{Definition and medical criteria for RTP}

The absence of clear and uniform definitions and medical criteria for RTP has been a methodological issue in studies of different musculoskeletal domains, such as RTP after anterior cruciate ligament injury, ankle injury and concussion. ${ }^{46-49}$ A clear definition of RTP is needed for consistency when investigating issues related to RTP, including reinjury risk factors, RTP prognostic factors and intervention programmes. ${ }^{22}{ }^{24-27}$ Differences in the definition and criteria for RTP after hamstring injury make it difficult to compare study results and lead to uncertainty about which findings should be implemented in clinical practice. ${ }^{22}$ The 2016 consensus statement on return to sport defined RTP as a continuum comprising three key elements-return to participation, return to preinjury sport and return to performance. ${ }^{50}$ This approach complements criteria-based rehabilitation, and considers the entire rehabilitation and recovery process, including the phase beyond return to sport where the athlete returns to his/her desired performance level. ${ }^{50}$ However, it is important to differentiate between the return to sport process and the final RTP decision, where RTP is viewed as an endpoint (or primary outcome). This Delphi study explicitly focused on the final RTP decision (when is the player fully available for match selection and full training) and involved consensus among experts in the field of prevention and treatment of hamstring injuries in football. Although not yet studied and validated in clinical practice, this Delphi study may help clinicians faced with the problem of when an athlete should RTP after a hamstring injury. Furthermore, both the definition and criteria can be used in research, potentially leading to greater uniformity and promoting comparability of research.

\section{Medical criteria for RTP after hamstring injury}

Absence of pain and psychological readiness

Absence of pain on palpation of the hamstrings, during strength and flexibility testing, and during or after functional performance was considered important as pain may indicate incomplete tissue healing. Athletes with localised discomfort on palpation just after RTP following hamstring injury were four times (AOR: 3.95 ; 95\% CI: 1.38 to 11.37 ) more likely to sustain a reinjury than athletes without discomfort on palpation. ${ }^{20}$ However, pain perception is influenced by tissue damage and by cognitive factors such as fear of reinjury or fear of pain. ${ }^{5152}$ The fear of pain or reinjury generates avoidance behaviour. ${ }^{52} 53$ In addition, athletes mention fear of reinjury as the main reason for not returning to sport. ${ }^{54}$

The relationship between fear of reinjury and unsuccessful RTP led to the suggestion that psychological readiness be included in RTP guidelines. ${ }^{55-57}$ We included psychological readiness in both the definition and criteria for RTP after hamstring injury. The expert panel agreed that the psychological readiness of the player should be considered before RTP clearance. Studies focusing on other musculoskeletal injuries previously emphasised the importance of psychological readiness assessment as a part of the RTP decision. ${ }^{55-57}$ For example, the Knee Self-Efficacy Scale is recommended for the RTP evaluation of patients rehabilitating from an anterior cruciate ligament injury. ${ }^{58}$ However, there are no valid tools to quantify psychological readiness after hamstring injury rehabilitation. The potential relationship between psychological factors and RTP after hamstring injuries remains an important topic for future research.

\section{Similar hamstring strength and hamstring flexibility}

An isometric knee flexion force deficit just after RTP is associated with an increased risk of hamstring injury. ${ }^{20}$ Our expert panel did not reach consensus regarding whether 'similar eccentric hamstring strength' should be a criterion to support the RTP decision. Although there was consenus that other contraction modes should not be included as a criterion to support the RTP decision. Hamstring peak torque, quadriceps peak torque and conventional concentric hamstring:quadriceps ratios (as measured with different test speeds and muscle contractions) are not associated with an increased risk of hamstring reinjury. ${ }^{8}$ There is also no relationship between concentric hamstring to opposite hamstring $\left(\mathrm{H}: \mathrm{H}^{\mathrm{opp}}\right)$ ratio and hamstring reinjury. However, eccentric strength asymmetries are predictive of hamstring muscle injuries in football players. ${ }^{59}$ Furthermore, $67 \%$ of all football players clinically recovered from hamstring injuries had at least one hamstring isokinetic testing deficit of more than $10 \% .^{21}$ Thus elimination of isokinetic strength asymmetries is not a requirement for RTP, although it is not known whether isokinetic strength deficits are associated with the risk of hamstring reinjury. ${ }^{21}$

From a biomechanical perspective, strength is preferably measured in a (sub)maximally stretched position, for which a fair amount of hamstring extensibility is required. ${ }^{60-63}$ There is ongoing debate regarding the relationship between hamstring flexibility and risk of hamstring injury. ${ }^{78}$ Many studies have not found hamstring flexibility to be a risk factor for hamstring injury. ${ }^{8}{ }^{64}$ However, the H-test (an active hamstring flexibility test) showed promising results as a complement to clinical examination. ${ }^{65}$ Experts in our Delphi study stated that this test seems promising as it involves an active flexibility component as well as assessment of insecurity in the athlete. However, there was no consensus on the inclusion of this test to support the RTP decision because experts stated there was insufficient evidence to support the use of the test and because the test lacks functionality.

\section{Performance on field testing}

Performance on field testing was considered vital by the expert panel when assessing RTP readiness, as it mimics the actual sports requirements. Furthermore, many criteria-based hamstring injury rehabilitation protocols have suggested including performance-based criteria, such as a normal week of training sessions, ${ }^{66}$ sport-specific scenarios ${ }^{21}$ and functional phase training. ${ }^{17}$ As most hamstring injuries occur in the latter stages of a match or training, fatigue and its associated decline in functional performance need to be considered in addition to field testing. ${ }^{56768}$ Therefore, one could argue that both qualitative and quantitative assessments of functional 
performance should be performed in a fatigued state. ${ }^{14}$ Future research should focus on the development of a sport-specific test battery for RTP after hamstring injury, in which functional aspects, fatigue, hamstring flexibility, absence of pain and potentially hamstring strength are assessed in the light of the RTP decision.

\section{Hamstring RTP decision-making}

Owing to the complexity of RTP decision-making, as well as potential competing interests and different views of various stakeholders, it is commonly agreed that RTP decisions should be based on multidisciplinary consultation. ${ }^{23}{ }^{4169}$ Although the sports physician may be best qualified to synthesise medical information, step 3 of the Creighton model ${ }^{29}$ describes some important RTP decision modifiers (eg, financial interests, timing in season, internal pressure, etc). Generally, the sports physician is only responsible for the medical part of the RTP decision and does not have the final say over these decision modifiers (such as financial, legal or team-tactical issues). Hence, the sports physician may have responsibility for the decision without authority to make it. ${ }^{69}$ Ultimately, the best interests of the athlete are decisive, and this covers more than just the medical risk assessment. ${ }^{28} 2941$ Therefore, in our opinion, different stakeholders with different views should be involved in the final RTP decision, bearing in mind the best interests of the athlete.

\section{Strengths and weaknesses of this study}

Delphi studies have the advantage of using the knowledge and expertise of participating experts to reach consensus. ${ }^{3070} 71$ This Delphi study involved a multidisciplinary sample of clinical and academic experts with extensive experience in hamstring injury research and rehabilitation. Although there is no scientifically proven minimally acceptable response rate, a response rate of $60 \%$ has been used as the threshold of acceptability. ${ }^{72}$ This Delphi consensus study had an excellent response rate of $>83 \%$ for each Delphi round.

The results of Delphi studies should be viewed in the light of the expert panel's opinion at any given point in time ${ }^{70}$ because opinions may change in the light of new evidence and paradigm shifts. ${ }^{73}$ Therefore, both the definition and criteria for RTP after hamstring injury should be re-evaluated in the future, based on new research findings.

When drafting this consensus, no limitations regarding (medical) staff and tools were considered. This makes the consensus more suitable for a professional setting compared with an amateur setting due to differences regarding team staff and (access to) tools such as GPS tracking systems. Teams with limited access to a comprehensive team staff are advised to still consider and acknowledge the multifaceted nature of the RTP decision, as discussed in this manuscript. This Delphi consensus procedure additionally advised simpler functional tests if GPS tracking systems and/or speed measurement equipment is unavailable (eg, repeated sprint ability test, deceleration drills, etc), although GPS tracking systems are considered an important tool for functional assessment by the majority of our expert panel due to their ability to mimic sport-specific function.

This study provided medical criteria to assess the health status of the athlete. This is only the first step in the three-step RTP assessment after hamstring injury (see figure 1). ${ }^{28} 29$ In addition to the health status evaluation, the assessment of tissue stresses (from type of sport, level of play, etc) and RTP decision modifiers (timing and season, pressure from the athlete or external, financial issues, etc) should form a solid basis for RTP decision-making. ${ }^{28} 29$

\section{Clinical relevance}

Although experts' opinions are considered a low level of evidence, we consider this study to be an important first step in standardising and improving the final RTP decision after hamstring injury. In addition, the criteria to support the RTP decision were generated by clinical and academic authorities in the field of hamstring injury management. These criteria will help both clinicians and (clinical) researchers to assess the risk of RTP after hamstring injury.

\section{Future research}

There is a need for high-quality prospective research to validate RTP criteria. Considering the multidimensional nature of hamstring injuries, RTP criteria should not be validated as univariate factors, but interaction between criteria as well as the varying weighting of criteria due to time and circumstances needs to be considered. ${ }^{745}$

\section{CONCLUSION}

A panel of 58 international experts reached consensus regarding RTP terminology, definition, medical criteria, responsibilities and consultation for RTP after hamstring injuries in football. The results are reported in the RTP model for hamstring injuries in football. The RTP decision should always be a multidisciplinary decision. For RTP readiness assessment of the player after a hamstring injury, emphasis is placed on pain relief, flexibility assessment, psychological readiness and functional performance. MRI findings should not be used for $\mathrm{RTP}$ readiness assessment.

Acknowledgements The authors would like to thank FIFA and the FIFA Medical Centres of Excellence network for their support and cooperation in expert selection and recruitment.

Collaborators The collaborators of HIPS-Delphi group include: CSA Ahmad (USA); TEA Andersen (Norway); JP Araujo (Portugal); FE Arroyo (Mexico); CM Askling (Sweden); PD Batty (UK); BB Bayraktar (Turkey); CB Beckmann (Germany); M Bizzini (Sweden); M Cohen (Brazil); SPC Connelly (UK); D Constantinou (South Africa): AS Edwards (UK); J Espregueira-Mendes (Portugal); DJ Exeter (New Zealand); ML Fulcher (New Zealand); aus der Fünten (Germany); WE Garrett (USA); M Grygorowicz (Poland); TB Haag (Germany), R Hejna (Poland); JM Houghton (UK); Al Isik

(Turkey); S Kemp (UK); C Kruiswijk (Netherlands); GG Lewin (UK); T Lewis (UK); M Lichaba (South Africa); N Loureiro (Portugal); RL Loursac (France); NAM Maffiuletti (Sweden); AM Marles (France); J Mendiguchia (Spain); NM Miyauchi (Japan); HM Moksnes (Norway): CS Motaung (South Africa); EN Noel (France); GJ O'Driscoll (UK); TO Okuwaki (Japan); K Peers (Belgium); T Piontek (Poland); R Pruna (Spain); Ranson CA (UK); YS Saita (Japan); MB Santos (Brazil); CS Schneider (Germany); KS Schwarzenbrunner (Austria); HJ Silvers (USA); A Stålman (Sweden); EV van den Steen (Belgium); S Sundelin (Sweden); JL Tol (Qatar); NJ Veldman (Netherlands); R Weiler (UK); R Whiteley (Qatar); E Witvrouw (Qatar); A Yekdah (Algeria); JE Zachazewski (USA).

Contributors Four authors have made substantial contributions to this manuscript: $\mathrm{NH}, \mathrm{EAG}, \mathrm{BMAH}$ and FJGB. They have all participated in the concept and design, analysis and interpretation of data, and drafting and revising the manuscript. All authors have read the manuscript and agreed to submission for publication. The HIPS-Delphi Group, the name of our expert panel, contributed to the full contents of the consensus. We would therefore like to acknowledge the 'HIPS-Delphi Group' with authorship as well.

Competing interests None declared.

Provenance and peer review Not commissioned; externally peer reviewed.

(c) Article author(s) (or their employer(s) unless otherwise stated in the text of the article) 2017. All rights reserved. No commercial use is permitted unless otherwise expressly granted. 


\section{REFERENCES}

1 Ekstrand J, Waldén M, Hägglund M. Hamstring injuries have increased by $4 \%$ annually in men's professional football, since 2001: a 13-year longitudinal analysis of the UEFA Elite Club injury study. Br J Sports Med 2016;50:731-7.

2 Hägglund M, Waldén M, Ekstrand J. Injuries among male and female elite football players. Scand J Med Sci Sports 2009;19:819-27.

3 Ekstrand J, Hägglund M, Waldén M. Epidemiology of muscle injuries in professional football (soccer). Am J Sports Med 2011;39:1226-32.

4 van Beijsterveldt AM, van de Port IG, Krist MR, et al. Effectiveness of an injury prevention programme for adult male amateur soccer players: a cluster-randomised controlled trial. Br J Sports Med 2012;46:1114-8.

5 Woods C, Hawkins RD, Maltby S, et al; Football Association Medical Research Programme. The Football Association Medical Research Programme: an audit of injuries in professional football--analysis of hamstring injuries. Br J Sports Med 2004;38:36-41.

6 Hägglund M, Waldén M, Magnusson $\mathrm{H}$, et al. Injuries affect team performance negatively in professional football: an 11-year follow-up of the UEFA Champions League injury study. Br J Sports Med 2013;47:738-42.

7 van Beijsterveldt AM, van de Port IG, Vereijken AJ, et al. Risk factors for hamstring injuries in male soccer players: a systematic review of prospective studies. Scand J Med Sci Sports 2013;23:253-62.

8 Freckleton G, Pizzari T. Risk factors for hamstring muscle strain injury in sport: a systematic review and meta-analysis. Br J Sports Med 2013;47:351-8.

9 Koulouris G, Connell DA, Brukner $\mathrm{P}$, et al. Magnetic resonance imaging parameters for assessing risk of recurrent hamstring injuries in elite athletes. Am J Sports Med 2007;35:1500-6.

10 Brooks JH, Fuller CW, Kemp SP, et al. Incidence, risk, and prevention of hamstring muscle injuries in professional rugby union. Am J Sports Med 2006;34:1297-306.

11 Ekstrand J, Gillquist J. Soccer injuries and their mechanisms: a prospective study. Med Sci Sports Exerc 1983;15:267-70.

12 Werner J, Hägglund $M$, Waldén $M$, et al. UEFA injury study: a prospective study of hip and groin injuries in professional football over seven consecutive seasons. Br J Sports Med 2009:43:1036-40.

13 Orchard JW, Seward H, Orchard JJ. Results of 2 decades of injury surveillance and public release of data in the Australian Football League. Am J Sports Med 2013:41:734-41.

14 Opar DA, Williams MD, Shield AJ. Hamstring strain injuries: factors that lead to injury and re-injury. Sports Med 2012;42:209-26.

15 de Visser HM, Reijman M, Heijboer MP, et al. Risk factors of recurrent hamstring injuries: a systematic review. Br J Sports Med 2012;46:124-30.

16 Wangensteen $A$, Tol JL, Witvrouw $E$, et al. Hamstring reinjuries occur at the same location and early after return to sport: a descriptive study of MRI-confirmed reinjuries. Am J Sports Med 2016;44:2112-21.

17 Mendiguchia J, Brughelli M. A return-to-sport algorithm for acute hamstring injuries. Phys Ther Sport 2011;12:2-14.

18 Orchard J, Best TM, Verrall GM. Return to play following muscle strains. Clin J Sport Med 2005;15:436-41.

19 Reurink G, Goudswaard GJ, Tol JL, et al. MRI observations at return to play of clinically recovered hamstring injuries. Br J Sports Med 2014;48:1370-6.

20 De Vos RJ, Reurink G, Goudswaard GJ, et al. Clinical findings just after return to play predict hamstring re-injury, but baseline MRI findings do not. Br J Sports Med 2014:48:1377-84.

21 Tol JL, Hamilton B, Eirale C, et al. At return to play following hamstring injury the majority of professional football players have residual isokinetic deficits. $\mathrm{Br} J$ Sports Med 2014;48:1364-9.

22 van der Horst N, van de Hoef S, Reurink G, et al. Return to play after hamstring injuries: a qualitative systematic review of definitions and criteria. Sports Med 2016;46:899-912

23 Shultz R, Bido J, Shrier I, et al. Team clinician variability in return-to-play decisions. Clin J Sport Med 2013;23:456-61.

24 Finch CF. An overview of some definitional issues for sports injury surveillance. Sports Med 1997;24:157-63.

25 Junge A, Dvorak J. Influence of definition and data collection on the incidence of injuries in football. Am J Sports Med 2000;28(Suppl 5):40-6.

26 Fuller CW, Ekstrand J, Junge A, et al. Consensus statement on injury definitions and data collection procedures in studies of football (soccer) injuries. Br J Sports Med 2006:40:193-201.

27 Brooks JH, Fuller CW. The influence of methodological issues on the results and conclusions from epidemiological studies of sports injuries: illustrative examples. Sports Med 2006;36:459-72

28 Shrier I. Strategic assessment of risk and risk tolerance (StARRT) framework for returnto-play decision-making. Br J Sports Med 2015;49:1311-5.

29 Creighton DW, Shrier I, Shultz R, et al. Return-to-play in sport: a decision-based model. Clin J Sport Med 2010;20:379-85.

30 Hasson F, Keeney S, McKenna H. Research guidelines for the Delphi survey technique. J Adv Nurs 2000;32:1008-15.

31 Powell C. The Delphi technique: myths and realities. J Adv Nurs 2003;41:376-82
32 Dalkey N, Brown B, Cochran S. The Delphi method, III: use of self ratings to improve group estimates. Santa Monica, CA: RAND Corporation, 1969. Publication RM-6115PR.

33 Weir A, Brukner P, Delahunt E, et al. Doha agreement meeting on terminology and definitions in groin pain in athletes. Br J Sports Med 2015;49:768-74.

34 Sullivan SJ, Schneiders AG, McCrory P, et al. Physiotherapists' use of information in identifying a concussion: an extended Delphi approach. Br J Sports Med 2008:42:175-7.

35 Donaldson A, Cook J, Gabbe B, et al. Bridging the gap between content and context: establishing expert consensus on the content of an exercise training program to prevent lower-limb injuries. Clin J Sport Med 2015;25:221-9.

36 Kleynen M, Braun SM, Bleijlevens MH, et al. Using a Delphi technique to seek consensus regarding definitions, descriptions and classification of terms related to implicit and explicit forms of motor learning. PLoS One 2014;9:e100227.

37 Huisstede BM, Hoogvliet P, Coert JH, et al; European HANDGUIDE Group. Multidisciplinary consensus guideline for managing trigger finger: results from the European HANDGUIDE study. Phys Ther 2014;94:1421-33.

38 Weir A, Hölmich P, Schache AG, et al. Terminology and definitions on groin pain in athletes: building agreement using a short Delphi method. Br J Sports Med 2015;49:825-7.

39 Verhagen AP, de Vet HC, de Bie RA, et al. The Delphi list: a criteria list for quality assessment of randomized clinical trials for conducting systematic reviews developed by Delphi consensus. J Clin Epidemiol 1998:51:1235-41.

40 Shrier I, Charland L, Mohtadi NG, et al. The sociology of return-to-play decision making: a clinical perspective. Clin J Sport Med 2010;20:333-5.

41 Shrier I, Safai P, Charland L. Return to play following injury: whose decision should it be? Br J Sports Med 2014;48:394-401.

42 Muyor JM, Vaquero-Cristóbal R, Alacid F, et al. Criterion-related validity of sit-andreach and toe-touch tests as a measure of hamstring extensibility in athletes.. $J$ Strength Cond Res 2014;28:546-55.

43 Impellizzeri FM, Rampinini E, Castagna C, et al. Validity of a repeated-sprint test for football. Int J Sports Med 2008;29:899-905.

44 Reurink G, Whiteley R, Tol JL. Hamstring injuries and predicting return to play: 'byebye MRI?'. Br J Sports Med 2015;49:1162-3.

45 Wangensteen A, Almusa E, Boukarroum S, et al. MRI does not add value over and above patient history and clinical examination in predicting time to return to sport after acute hamstring injuries: a prospective cohort of 180 male athletes. $\mathrm{Br}$ J Sports Med 2015;49:1579-87.

46 Grassi A, Zaffagnini S, Marcheggiani Muccioli GM, et al. After revision anterior cruciate ligament reconstruction, who returns to sport? A systematic review and meta-analysis. Br J Sports Med 2015;49:1295-304

47 Warner SJ, Smith MV, Wright RW, et al. Sport-specific outcomes after anterior cruciate ligament reconstruction. Arthroscopy 2011;27:1129-34.

48 Clanton TO, Matheny LM, Jarvis $\mathrm{HC}$, et al. Return to play in athletes following ankle injuries. Sports Health 2012;4:471-4.

49 Echemendia RJ, Giza CC, Kutcher JS. Developing guidelines for return to play: consensus and evidence-based approaches. Brain Inj 2015;29:185-94.

50 Ardern CL, Glasgow P, Schneiders A, et al. 2016 Consensus statement on return to sport from the First World Congress in Sports Physical Therapy, Bern. Br J Sports Med 2016:50:853-64

51 Niederstrasser NG, Meulders A, Meulders M, et al. Pain catastrophizing and fear of pain predict the experience of pain in body parts not targeted by a delayed-onset muscle soreness procedure. J Pain 2015;16:1065-76

52 Meulders A, Vansteenwegen D, Vlaeyen JW. The acquisition of fear of movementrelated pain and associative learning: a novel pain-relevant human fear conditioning paradigm. Pain 2011;152:2460-9.

53 Geisser ME, Haig AJ, Wallbom AS, et al. Pain-related fear, lumbar flexion, and dynamic EMG among persons with chronic musculoskeletal low back pain. Clin J Pain 2004:20:61-9.

54 Kvist J, Ek A, Sporrstedt K, et al. Fear of re-injury: a hindrance for returning to sports after anterior cruciate ligament reconstruction. Knee Surg Sports Traumatol Arthrosc 2005; 13:393-7.

55 Podlog L, Heil J, Schulte S. Psychosocial factors in sports injury rehabilitation and return to play. Phys Med Rehabil Clin N Am 2014;25:915-30.

56 Lentz TA, Zeppieri G, George SZ, et al. Comparison of physical impairment, functional, and psychosocial measures based on fear of reinjury/lack of confidence and return-to-sport status after $\mathrm{ACL}$ reconstruction. Am J Sports Med 2015;43:345-53.

57 Ardern CL, Taylor NF, Feller JA, et al. A systematic review of the psychological factors associated with returning to sport following injury. Br J Sports Med 2013;47:1120-6.

58 van Melick N, van Cingel RE, Brooijmans F, et al. Evidence-based clinical practice update: practice guidelines for anterior cruciate ligament rehabilitation based on a systematic review and multidisciplinary consensus. Br J Sports Med 2016:50:1506-15.

59 Fousekis K, Tsepis E, Poulmedis $\mathrm{P}$, et al. Intrinsic risk factors of non-contact quadriceps and hamstring strains in soccer: a prospective study of 100 professional players. $\mathrm{Br} J$ Sports Med 2011;45:709-14. 
60 Chumanov ES, Heiderscheit BC, Thelen DG. The effect of speed and influence of individual muscles on hamstring mechanics during the swing phase of sprinting. J Biomech 2007;40:3555-62.

61 Chumanov ES, Heiderscheit BC, Thelen DG. Hamstring musculotendon dynamics during stance and swing phases of high-speed running. Med Sci Sports Exerc 2011;43:525-32.

62 Proske U, Morgan DL, Brockett CL, et al. Identifying athletes at risk of hamstring strains and how to protect them. Clin Exp Pharmacol Physiol 2004;31:546-50.

63 Brockett CL, Morgan DL, Proske U. Human hamstring muscles adapt to eccentric exercise by changing optimum length. Med Sci Sports Exerc 2001;33:783-90.

64 van Doormaal MC, van der Horst N, Backx FJ, et al. No relationship between hamstring flexibility and hamstring injuries in male amateur soccer players. Am J Sports Med 2017;45:121-6.

65 Askling CM, Nilsson J, Thorstensson A. A new hamstring test to complement the common clinical examination before return to sport after injury. Knee Surg Sports Traumatol Arthrosc 2010;18:1798-803.

66 Valle $X$, Tol JL, Hamilton B, et al. Hamstring muscle injuries, a rehabilitation protoco purpose. Asian J Sports Med 2015;6:e25411.
67 Mair SD, Seaber AV, Glisson RR, et al. The role of fatigue in susceptibility to acute muscle strain injury. Am J Sports Med 1996;24:137-43.

68 Croisier JL. Factors associated with recurrent hamstring injuries. Sports Med 2004;34:681-95

69 Matheson GO, Shultz R, Bido J, et al. Return-to-play decisions: are they the team physician's responsibility? Clin J Sport Med 2011;21:25-30.

70 Keeney S, Hasson F, McKenna H. Consulting the oracle: ten lessons from using the Delphi technique in nursing research. J Adv Nurs 2006;53:205-12.

71 Mullen PM. Delphi: myths and reality. J Health Organ Manag 2003;17:37-52.

72 Johnson TP, Wislar JS. Response rates and nonresponse errors in surveys. JAMA 2012;307:1805-6

73 Quatman CE, Quatman CC, Hewett TE. Prediction and prevention of musculoskeletal injury: a paradigm shift in methodology. Br J Sports Med 2009;43:1100-7.

74 Mendiguchia J, Alentorn-Geli E, Brughelli M. Hamstring strain injuries: are we heading in the right direction? Br J Sports Med 2012:46:81-5.

75 Bittencourt NF, Meeuwisse WH, Mendonça LD, et al. Complex systems approach for sports injuries: moving from risk factor identification to injury pattern recognitionnarrative review and new concept. Br J Sports Med 2016;50:1309-14. 